\title{
PSICOLOGIA E EDUCAÇÃO: UM ESTUDO SOBRE O DESENVOLVIMENTO DO COMPORTAMENTO NA INFÂNCIA
}

\author{
PSICOLOGÍA Y EDUCACIÓN: UN ESTUDIO SOBRE EL DESARROLLO DEL \\ COMPORTAMIENTO EN LA INFANCIA
}

\section{PSYCHOLOGY AND EDUCATION: A STUDY ABOUT THE IMPROVEMENT OF CHILDHOOD BEHAVIOR}

DOI: http://dx.doi.org/10.9771/gmed.v11i2.28847

\author{
Júlio Ribeiro Soares ${ }^{1}$ \\ Gessica Fabiely Fonseca ${ }^{2}$ \\ João Victor da Silva Faustino ${ }^{3}$ \\ Samyr Damasceno Bonifácio ${ }^{4}$ \\ Luiz Roberto Fernandes ${ }^{5}$
}

Resumo: O artigo discute a concepção de desenvolvimento do comportamento na obra "sobre a questão da dinâmica do caráter infantil", escrita por Vigotski em 1928, e sua relação com o processo educacional. Realizado a partir de leitura em grupo, o estudo resultou na discussão e sistematização de três eixos: o primeiro, relacionado à concepção naturalizante do caráter; o segundo, aos desafios metodológicos; o terceiro, à mediação do processo educativo. Por fim, discute a formação do caráter como processo mediado pela existência da criança, inclusive no que diz respeito à sua educação.

Palavras-chave: Educação; Historicidade; Desenvolvimento.

Resume: El artículo discute la concepción del desenvolvimiento del comportamiento en la obra "sobre la cuestión de la dinámica del carácter infantil ", escrito por Vygotsky en 1928, y su relación con el proceso educativo. Realizado a partir de lectura en grupo, el estudio otorgó lugar a la discusión y sistematización de tres ejes: primero, en relación con la concepción naturalista del carácter; segundo, a los desafíos metodológicos; el tercero, la mediación del proceso educativo. Por fin, discute la formación del carácter como un proceso mediado por la existencia del infante, incluso con respecto a su educación.

Palabras clave: Educación; Historicidad; Desarrollo.

Abstract: The article debate the conception of development behavior in the reference work "Around the question of infancy character dynamics", written by Vigotski in 1928, and your relation with the educational process. Designed from a group review, the study results on the discussion and systematization of three pivots: the first, related a character naturalizing conception, the second, to the methodological objections; the third, through the educative process mediations. To conclude, it argues in respect to the character arrangement as a process mediated for the child existence, inclusive of what it assert in respect of their education.

Keywords: Education; Historicity; Development.

\section{Introdução}

Iniciamos este artigo citando Vigotski (2004, p. 389) quando aponta que "a possibilidade da psicologia como ciência é, antes de mais nada, um problema metodológico" (2004, p. 389). Esse apontamento é caro à educação, especialmente a escolar, cujo processo pedagógico, diferente do processo 
noutras formas de educação, é constituído tanto de bases epistemológicas quanto de práticas sistematizadas, fato esse que requer conhecimento em psicologia educacional.

Embalados na ideia vigotskiana acima colocada, esclarecemos que o uso do termo comportamento no título e mais em algumas passagens deste trabalho não é indicador de equiparação entre o campo psicológico e a manifestação empírica do indivíduo. Tem a ver com o fato de ser um termo recorrentemente utilizado por Vigotski (2006) na obra "Sobre a questão da dinâmica do caráter infantill, objeto de estudo neste artigo.

Isto posto, o objetivo deste é artigo discutir a concepção de desenvolvimento do comportamento na obra "sobre a questão da dinâmica do caráter infantil", escrita por Vigotski em 1928, e sua relação com o processo educacional. Para isso, também recorremos a leitura de outras obras do próprio Vigotski e de outros estudiosos no campo da Psicologia Sócio-Histórica.

Este artigo está dividido em três partes. Na primeira, analisamos a relação entre psicologia e educação, a partir da perspectiva sócio-histórica. $\mathrm{Na}$ segunda, tecemos considerações sobre a análise das funções psicológicas superiores. Na terceira, enfocamos o desenvolvimento do caráter infantil como fenômeno mediado pela realidade. Finalizamos com uma reflexão sobre a questão social e histórica do caráter.

\section{Psicologia e educação: a construção social e histórica do humano}

Constituindo a base da educação, a psicologia implica o processo pedagógico em todas as suas dimensões possíveis, seja na perspectiva de compreender os aspectos psicológicos do processo de aprendizagem e desenvolvimento, seja em possibilitar a construção de elementos pedagógicos para fomentar esse processo. Assim, quando aponta "a possibilidade da psicologia como ciência", Vigotski (2004) também denota, mesmo que indiretamente, a possibilidade da educação, uma vez que o conhecimento em psicologia é um dos fundamentos à compreensão do humano e da sistematização dos processos pedagógicos que, em tese, podem contribuir com o desenvolvimento das nossas funções psíquicas superiores.

Nesta discussão, nos fundamentamos na Psicologia Sócio-Histórica, conforme pode ser constatado pela recorrência a Vigotski. Apoiada numa perspectiva dialética e histórica, foi a psicologia proposta por Vigotski que possibilitou uma nova leitura do psiquismo humano, permitindo compreendê-lo como fenômeno que se constitui no movimento de existência dos indivíduos.

Quando apontamos o psiquismo como movimento, estamos nos referindo a uma construção histórica do humano. Na Psicologia Sócio-Histórica, a historicidade é uma categoria teórica e metodológica que define a realidade como processo, um fenômeno em transformação. Com base nessa categoria, Löwy (2015, p. 22) explica que "tudo o que existe na vida humana e social está em perpétua transformação, tudo é perecível, tudo está sujeito ao fluxo da história”. Assim, o humano se transforma não apenas porque é implicado pelas circunstâncias da vida cotidiana, mas também porque é mediado pela história da humanidade - e nesse caso inclui-se o psiquismo como um fenômeno histórico. Segundo Vigotski (2004, 
p. 396), "a psicologia não conta com vias de desenvolvimento independentes: é, pois, preciso buscar por trás dessas vias os processos históricos reais" que a configuram.

A tese de que "tudo o que existe na vida humana e social está em perpétua transformação" (LÖWY, 2015, p. 22) nos leva a outro recurso teórico e metodológico, a categoria atividade. A relação dialética entre atividade e historicidade pode ser explicada por Saviani (1997, p. 17) quando afirma que "o que não é garantido pela natureza tem que ser produzido historicamente pelos homens". É na atividade que a humanidade se constitui historicamente, materializando a sua existência para além do tempo presente, na forma de práticas sociais e culturais.

O que somos se constitui a partir da nossa atuação na realidade, transformando-a para satisfazer as nossas necessidades, ao mesmo tempo em que, nesse processo de transformação, também vamos nos transformando. Atividade e historicidade são mediações fundamentais do psiquismo humano.

Pensar o psiquismo humano a partir da atividade e da historicidade significa considerar que somos uma construção social. Ao mesmo tempo, essa condição social não anula a nossa condição de sujeito no mundo. A singularidade e a universalidade constituem-se dialeticamente, sendo mediadas pela historicidade. Significa que "o aspecto psíquico" que se constitui na atividade histórico não pode ser negligenciado, sob o risco de incorrer na velha dicotomia objetividade-subjetividade.

Reconhecendo que o objeto da psicologia é o psiquismo, Vigotski (2004) enfatiza que o erro da reflexologia (Pavlov e Bekhterev) foi ter ignorado o caráter ativo da consciência. Iarochevski e Gurguenidze (2004, p. 478) ajudam a explicitar essa questão quando apontam que Vigotski parte do "princípio de Marx de que no processo de trabalho, o homem, antes de obter um produto terminado, já dispõe de uma imagem desse produto".

O olhar de Vigotski sobre esse princípio em Marx implica um importante passo no desenvolvimento de sua posição teórica, que se distancia da ideia de o comportamento como formação reflexa condicionada, e se aproxima do "papel da consciência na organização e direção do comportamento" (IAROCHEVSKI e GURGUENIDZE, 2004, p. 479). Com isso, Vigotski caminha em direção ao estudo do significado (e não do signo), definido, segundo os referidos autores (p. 85), como "princípio organizador do desenvolvimento da consciência".

Não sendo um fenômeno natural nem reflexo especular da realidade, a consciência constitui-se pela forma como vamos nos apropriando do significado da nossa existência e convertendo-o em fenômeno psicológico. E nesse processo de constituição, a educação, especialmente a escolar, cumpre um papel fundamental, tendo em vista que é por meio dela que nos apropriamos da cultura e criamos as condições objetivas para nos desenvolvermos. A educação possibilita mudanças nos indivíduos que jamais seriam possíveis se fossem deixadas a ocorrer naturalmente.

Mas um ponto que ainda merece destaque sobre essa concepção de educação é aquele que diz respeito a relações sociais entre indivíduos. Embora as relações sociais não se restrinjam a relações entre pessoas, pois abrangem todo o campo da produção histórica da humanidade, nesse momento estamos nos referindo especificamente a esse tipo de relações, tendo em vista a importância do outro no nosso processo educacional. Essa importância pode ser confirmada em Bock, Furtado e Teixeira (2018, p. 149) quando 
apontam, por exemplo, que a aprendizagem, na perspectiva colocada por Vigotski, "sempre inclui relações entre as pessoas". Ainda segundo os referidos autores (2018, p. 149-150), "não há como aprender e apreender o mundo se não existir o outro, aquele que nos fornece significados que nos permitem pensar o mundo a nossa volta”.

Assim, é apenas na relação do indivíduo com o "outro" que os processos educativos se constituem. Como pontua Vigotski (2007, p. 56), só “nos tornamos nós mesmos através dos outros”. É apenas pela mediação do outro, que participa ativamente da nossa vida, que nos educamos, nos constituímos como pessoas, ao passo em que também participamos da sua educação.

A relação com o outro, contudo, não é direta. As relações entre as pessoas só se tornam possíveis pela linguagem, que regula não apenas a comunicação, mas, sobretudo, a forma como o pensamento se constitui como sistema ativo na apropriação e produção de significado, aqui entendido, conforme já citado anteriormente (VIGOTSKI, 2004), como "princípio organizador do desenvolvimento da consciência".

Cabe ressaltar que, por não se encerrar no campo linguístico, pois trata-se de um processo que se estende para o campo do pensamento, o significado se refere tanto ao significado propriamente dito quanto ao sentido (VIGOTSKI, 2001; 2004). No primeiro caso, entende-se o significado como um processo generalizável do pensamento, o que torna possível a comunicação entre as pessoas. No segundo, o significado tem uma função mais dinâmica e subjetiva, constituindo-se como uma produção singular mediada pela existência do indivíduo.

Destacando o papel do "outro" no processo de educacional, partimos do pressuposto de que a educação tem papel fundante na formação das nossas características tipicamente humanas. Salvas as devidas nuances maturacionais e biológicas que nos constituem, essas características são fundamentalmente mediadas por processos sociais e históricos, o que inclui processos educacionais e a maneira como nos apropriamos e significamos a realidade a partir das relações com as pessoas.

\section{Análise das funções psicológicas superiores: princípios metodológicos}

No estudo sobre "problemas de método", Vigotski (2007, p. 63) discorre sobre três princípios que "formam a base de nossa abordagem na análise das funções psicológicas superiores”. Esses princípios ajudam a entender que a formação do caráter, longe de ser naturalmente determinada, é um fenômeno histórico, social e dialético.

Vigotski (2007) aponta, logo no primeiro princípio, que é necessário analisar processos, e não objetos. Com isso, enfatiza que as funções psicológicas superiores - e nesse caso inclui-se a formação do caráter constituem-se como um sistema dinâmico e em movimento, cujo processo é marcado não por uma linearidade de eventos e saltos qualitativos, mas também crises e distúrbios.

O segundo princípio trata da explicação versus descrição. De acordo com esse princípio, a descrição se limita a manifestação do fenômeno, isto é, ao que se encontra aparentemente perceptível. Assim sendo, a descrição não permite apreender a complexidade do fenômeno em desenvolvimento. O que importa à psicologia é, portanto, explicar o fenômeno, e não apenas descrevê-lo. 
O problema do comportamento fossilizado é o terceiro princípio. Do ponto de vista procedimental, esse é, possivelmente, o mais complexo dentre os outros dois princípios. Refere-se a comportamentos que, em decorrência do tempo, tornaram-se automatizados. Segundo Vigotski (2007, p. 67), esse princípio refere-se a processos psicológicos "que esmaeceram ao longo do tempo". A forma fossilizada de um comportamento superior não significa que ele tenha se constituído naturalmente. Sendo um processo histórico e dinâmico, toda forma de comportamento superior pode, portanto, ser alterada pela mediação da atividade sóciohistórica que constitui o indivíduo e a sociedade.

\section{Análise de Vigotski: contribuições ao estudo da formação do caráter infantil}

A produção deste artigo consistiu num estudo da obra "sobre a questão da dinâmica do caráter infantil" (Vigotski, 2006), por meio de algumas estratégias, como leitura em grupo, recorte da obra, com levantamento de questões para discussão.

A partir da articulação das questões levantadas, considerando a existência de "pontos temáticos" que apresentam semelhanças que as aproximam, sintetizamos o estudo em três eixos: o primeiro, relacionado às concepções naturalizantes do caráter; o segundo, aos desafios metodológicos; o terceiro, que trata da mediação do processo educativo.

\section{- Questionando a concepção naturalizante do caráter infantil}

Logo no início do texto, Vigotski (2006) questiona a forma como as teorias pedagógicas e psicológicas concebiam, na sua época, o caráter infantil. É um questionamento que, de alguma forma, acompanha a sua análise ao longo do texto. Segundo Vigotski (2006, p. 280), a questão, nas teorias vigentes, "era tratada de forma estática, analisando-se o caráter como uma dimensão estável, sempre igual a si mesma, dada e presente".

Havia o entendimento de que o caráter era uma condição inata, estaticamente formada no indivíduo. A partir desse entendimento, era descartável qualquer hipótese de estudo que considerasse o caráter como uma característica tipicamente humana que se desenvolve numa perspectiva de transformação. Por isso, o autor (2006, p. 280) afirma que o caráter "era entendido como um estado e não como um processo, como condição e não como um devir".

Vigotski (2006) cita o nome de três importantes estudiosos que determinam, de alguma forma, o embasamento teórico e metodológico sobre a concepção de caráter que se constitui, naquele momento inicial do século XX, como compreensão hegemônica sobre o assunto: Théodule Ribot, Ernst Kretschmer e Pavel Blonski. Embora fossem de nacionalidades diferentes, e cada um tenha elaborado suas próprias concepções, suas ideias se complementam, especialmente no que diz respeito aos aspectos estáticos do caráter. Por isso, suas ideias formam uma concepção, e não diferentes concepções.

Não vamos adentrar em detalhes sobre esses estudiosos. Mas nos interessa destacar que Vigotski (2006) aponta que, embora haja diferença entre eles, a estabilidade do caráter é um princípio intocável em 
suas teorias sobre o caráter. Assim, Vigotski (2006, p. 280) pontua que, de acordo com os referidos estudiosos, “a série de tipos estáveis pelos quais a criança passa, sucessivamente, é [...] estática e não uma serie dinâmica. E essa é a característica principal tanto de um como do outro estudo”.

A concepção de que o caráter é estável denota implicações sobre a compreensão do que seja o psiquismo humano, cujo desenvolvimento é interpretado como uma evolução natural. Assim, a história do comportamento de uma criança não significa, para essa perspectiva, a história de ações e transformações, uma vez que a história, nesse caso, significa apenas o registro de fatos passados.

Mesmo que ainda não tivesse se descolado da base reflexológica de Pavlov nesse momento (1928), importantes passos já eram dados por Vigotski (2006, p. 281) na construção de uma nova psicologia, conforme podemos apreender desse seu questionamento abaixo, que carrega na base a questão metodológica:

A imperfeição desse ponto de vista, como de qualquer outro que seja estático e não dinâmico, é que ele é incapaz de solucionar questões sobre a origem, o desenvolvimento, o curso e é obrigado a limitar-se à constatação, reunião, generalização e classificação de dados empíricos.

Com uma visão dialética e histórica que o permite compreender que o desenvolvimento humano não é um ato evolutivo, mas um fenômeno em transformação, Vigotski assume uma posição metodológica que é ontológica, cuja preocupação é a gênese da formação do comportamento, e não a "constatação, reunião, generalização e classificação de dados empíricos”.

Isso posto, as concepções naturalizantes e estáticas sobre o caráter passam a ser criticamente questionadas por Vigotski (2006, p. 283), conforme podemos constatar quando diz que "jamais compreenderemos a fundo a personalidade humana se a analisarmos estaticamente como uma soma de manifestações, condutas etc.".

Esse pensamento de Vigotski pode ser melhor apreendido a partir dos princípios metodológicos anteriormente discutidos neste artigo, especialmente o primeiro, segundo o qual devemos analisar o psiquismo como um processo, e não como um produto. Assim, o que se vislumbra nessa discussão é a necessidade de uma psicologia que construa aportes que permitam compreender o humano como um sujeito em movimento, considerando sua história e projetos de vida.

\section{- Estudo do caráter infantil: desafios metodológicos}

No item anterior, algumas questões metodológicas já foram discutidas, partindo do pressuposto de que, para Vigotski (1928/2006), a possibilidade de superação da concepção naturalizante do caráter passa, fundamentalmente, pela questão metodológica, isto é, passa por mudança na questão de cunho científico, cujo propósito é compreender o comportamento humano não apenas como uma manifestação empírica, mas uma produção social e histórica que se materializa no individual.

Essa mudança, de cunho metodológico e científico, se faz necessário porque a realidade, inclusive o mundo psíquico, não se reduz apenas ao que pode ser "observado" e "fotografado". A realidade é muito mais complexa do que parece. Por isso, Vigotski (2006, p. 281), citando Marx e Engels na defesa do papel 
da ciência no estudo da realidade, explica que "se a forma de revelação e a essência das coisas coincidissem diretamente, então qualquer ciência seria desnecessária".

Frente a essa necessidade, do ponto de vista científico e metodológico de apreendermos a realidade para além da aparência, é que podemos avançar na compreensão da complexidade dos fenômenos que constituem o mundo humano em movimento, inclusive no que diz respeito à dinâmica de formação dos nossos muitos modos de comportamentos. Assim, segundo Vigotski (1928/2006, p. 281), "o ponto de vista que se contenta com a forma de "manifestação das coisas", ou seja, somente com os dados empíricos sem a análise de sua "essência", não é um ponto de vista científico. Tal versão sempre começa, fatalmente, pelo fim".

Quando diz que é necessário analisar da essência dos fenômenos, Vigotski (2006) se remete à necessidade metodológica de considerarmos à sua história, desde a sua origem, levando em conta que é na atividade que os fenômenos psicológicos se movimentam e, portanto, se transformam, vindo a se constituir no que são hoje. Noutras palavras, o que são hoje, o são pela mediação da historicidade. Essa questão pode ser explicada de maneira mais clara quando, fazendo uma analogia entre a biologia e a psicologia, Vigotski (2006, p. 281) explica que, "assim como a biologia começou com a origem das espécies, a psicologia deve começar pela origem dos indivíduos". Para ele, essa é a chave da psicologia.

Por isso, continua Vigotski (2006, p. 282), "para entender o caráter do mártir que vai com alegria para a fogueira, há que se perguntar sob que condições surgiu, necessariamente, esse caráter que leva o mártir a alegrar-se". Esse é um exemplo que pode ser bastante elucidativo não apenas sobre a formação do caráter de um mártir, mas sobre as diversas formas de comportamento que nos constituem. E na base dessa formação estão presentes muitas mediações sociais e históricas, objetivas e subjetivas, devendo-se considerar que o indivíduo não é um ser passivo. Ele tem um papel ativo nesse processo de constituição.

Por isso, na análise histórica do processo de constituição do sujeito, é fundamental considerar que se trata de um sujeito em atividade, que atua sobre a realidade material, transformando-a para atender as suas necessidades, fato esse que, ao atuar sobre a realidade, ele também se transforma, objetivando-se nela a partir da apropriação de suas propriedades. Por isso, segundo Vigotski (2006, p. 282), "a lógica do desenvolvimento do caráter é a mesma de qualquer desenvolvimento. Tudo que se desenvolve desenvolvese por necessidade".

\section{- A mediação social e educacional na formação do caráter}

Neste tópico, a nossa intenção é resgatar a articulação, na obra de Vigotski (2006), entre formação do caráter e processo educacional. Noutros termos, o que objetivamos é apreender a mediação do processo educativo na formação do caráter infantil.

Numa das passagens centrais da obra "sobre a questão da dinâmica do caráter infantil", Vigotski (2006, p. 287) afirma que a criança "revela-se sempre incompleta na sociedade dos adultos". Essa afirmação é um ponto nodal para se compreender que a educação é uma atividade cuja finalidade é completar o que falta a criança. Mas, o que falta a criança? Conforme pontuado na citação acima, o que falta é definido pela 
"sociedade dos adultos". Por isso, Vigotski (2006, p. 287) assegura que "a perspectiva psicológica do futuro é a possibilidade teórica da educação".

Sendo incompleta, a criança precisa ser preparada para o futuro, para que possa atuar com autonomia nos mesmos espaços em que os adultos atuam. Contudo, isso é um processo lento, como afirma Vigotski (2006, p. 287): "Durante longos anos, a criança permanece inadaptada para a existência independente e nessa inadaptação e desconforto da infância está a raiz do seu desenvolvimento".

A criança é, portanto, um indivíduo em desenvolvimento; um indivíduo que, de forma ativa, supera a sua "incompletude". Assim, a sua inadaptação à "sociedade dos adultos" é um fenômeno que se transforma. Mas essa transformação não ocorre naturalmente.

Para explicar a ideia de "inadaptação", presente na teoria de Vigotski, recorremos ao autor (2006, p. 287), quando faz as seguintes ponderações: “A infância é a época de insuficiências e compensações por excelência, ou seja, da conquista de uma posição em relação ao todo social". As insuficiências, portanto, não são apenas impeditivas ao processo de desenvolvimento, uma vez que elas também são atravessadas por possibilidades de "compensações".

Sobre essa relação entre "insuficiência" e "compensação", Vigotski (2006, p. 287), utilizando a "deficiência da função auditiva" para ilustrar essa questão, explica: "por meio de formações reativas e compensações, desenvolve-se a sensibilidade mais apurada, a desconfiança, a inquietação, a curiosidade e outras funções para compensar" a deficiência. Segundo Vigotski (idem), cria-se "uma superestrutura psicológica de defesa".

Embora utilize, paradoxalmente, a expressão "processo natural de desenvolvimento e de formação da criança", e até recorra a metodologia do reflexo condicionado para explicar a questão da formação do caráter, entendemos, por meio da análise geral do texto, sobretudo quando critica explicitamente as teorias estáticas do caráter, que um salto qualitativo nesse estudo de Vigotski consiste na definição de que a noção de "superestrutura" acima mencionada não é um fenômeno natural, e sim um processo mediado pela atividade social vivida e apreendida pelo indivíduo.

"No processo dessa conquista", expressão utilizada para referir-se à "relação entre "insuficiência" e "compensação", Vigotski (2006, p. 287) aponta que "o ser humano, como um determinado biótipo, transforma-se em ser humano como um sociotipo, um organismo animal se converte em personalidade humana". As possibilidades dessa transformação estão na educação, ou como ele mesmo ressalta, "o domínio social desse processo natural [biótipo] é chamado de educação".

Ainda sobre essa questão que aborda a transformação do humano natural em social como processo mediado pela educação, cabe ressaltar, mesmo que muito brevemente, a importância da brincadeira na formação do caráter na criança. Para isso, Vigotski (2006) busca apoio no psicólogo Karl Gross, uma das grandes referências nos estudos sobre jogos. Ele se preocupa em compreender não apenas o modo pelo qual as crianças brincam, os tipos de brincadeiras de que participam ou o que utilizam para isso. A sua preocupação se volta para a origem do interesse em brincar. E essa origem, segundo Vigotski (2006, p. 288), tem a ver com a "insuficiência" de a criança se desenvolver naturalmente, isto é, "a brincadeira surge em 
função da insuficiência das reações inatas da criança para a realização de tarefas complexas vitais, ou seja, por causa da inadaptação".

Definida como um processo de compensação, e, portanto, de desenvolvimento, a brincadeira é o meio, segundo Vigotski (2006, p. 288), que "prepara a criança para o futuro, alicerça as linhas fundamentais de seu comportamento". Ao mesmo tempo, ressalta que a "ideia e a prática de tal brincadeira seriam impossíveis se o desenvolvimento da personalidade fosse um desencadeamento passivo dos impulsos primários inatos". Noutras palavras, a transformação do humano natural em social é mediada pela educação, o que inclui o processo do brincar na infância educacional.

\section{Considerações finais}

Conforme anunciado no início deste artigo, o nosso objetivo se pauta em discutir a concepção de desenvolvimento do comportamento na obra "sobre a questão da dinâmica do caráter infantil", escrita por Vigotski em 1928, e sua relação com o processo educacional. Trata-se de uma obra que foi publicada pelo autor em 1928. No Brasil, circula como um dos capítulos do livro "Fundamentos da defectología", volume $\mathrm{V}$ das Obras Completas publicadas pelo Editorial Pueblo e Educación. O material analisado neste estudo, todavia, é um artigo traduzido pela professora Zoia Prestes e que fora publicado, em 2006, na revista "Linhas Críticas", da Universidade de Brasília.

Além do objetivo principal deste artigo, outro objetivo que nos moveu neste estudo diz respeito ao interesse em dar visibilidade a essa obra de Vigotski, que, apesar da sua importância para o campo da educação, parece que ainda não foi descoberta por estudantes de algumas áreas, como psicologia e educação. Entre nós, autores deste material, a obra começou a ser estudada no início de 2018, na ocasião de um seminário de estudo, no curso de licenciatura em Ciências Biológicas da UFRN. Desde esse período, temos aprofundado a discussão que resulta neste artigo.

No seminário de estudo, a intenção era refletir não apenas sobre comportamentos que se manifestam entre estudantes na sala de aula, seja aqueles concebidos como negativos (indisciplina, irritação, etc.), seja aqueles que se definem como positivos (compromisso com os estudos, atenção às aulas, etc.), mas refletir criticamente sobre a origem desses fenômenos comportamentais que, por sua recorrência em sala de aula, tendem a ser naturalizados, principalmente quando são "julgados" como inadequados. Com isso, a perspectiva era refletir "sobre o caráter infantil” a partir da psicologia da educação. Mas não podíamos restringir a nossa reflexão ao campo das manifestações comportamentais. Era preciso, como sugere a obra analisada, apreender o caráter em profundidade, considerando a perspectiva de sua formação.

Este estudo sugere que, se quisermos compreender as formas comportamentais da criança, não basta descrever o que ela manifesta em sala de aula e, em seguida, qualifica-la como um tipo estranho, descolado do mundo vivido. Todo comportamento só pode ser explicado pela história que o constitui como humano, isto é, a partir da vivência social e histórica do indivíduo. Como afirma Vigotski (2006, p. 288), tendo Zalkind Borissovich como referência, "cada pessoa não só é uma unidade biológica, mas também 
histórica e carrega em seu caráter traços históricos". Essa é, possivelmente, uma das afirmações que melhor sintetiza nossa leitura e discussão sobre a obra de Vigotski aqui estudada.

\section{Referências}

BOCK, Ana M, B.; TEIXEIRA, Maria L. T.; FURTADO, Odair. Psicologias: uma introdução ao estudo de psicologia. São Paulo: Saraiva, 2018.

IAROCHEVSKI, M. F.; GURGUENDZE, G. S. Epílogo. In: VIGOTSKI, Lev S. Teoria e método em Psicologia. Ed. Martins Fontes, 2004.

LÖWY, Michael. Ideologias e Ciência Social: elementos para uma análise marxista. São Paulo: Cortez, 2015.

SAVIANI, Dermeval. Pedagogia histórico-crítica: primeiras aproximações. Campinas, SP: Autores Associados, 1997.

VIGOTSKI, Lev S. A construção do pensamento e da linguagem. São Paulo: Martins Fontes, 2001.

VIGOTSKI, Lev S. A formação social da mente: o desenvolvimento dos processos psicológicos superiores. São Paulo: Martins Fontes, 2007.

VIGOTSKI, Lev S. Teoria e método em psicologia. São Paulo: Martins Fontes, 2004.

VIGOTSKI, Liev S. Sobre a questão da dinâmica do caráter. Linhas críticas, Brasília, v. 12, n. 23, p. 279291, jul./dez. 2006.

\section{Notas}

${ }^{1}$ Universidade Federal do Rio Grande do Norte - UFRN. Professor do Departamento de Fundamentos e Políticas da Educação do Centro de Educação da Universidade Federal do Rio Grande do Norte. Orcid: http://orcid.org/0000-0002-3288-7756 Email: julioribeirosoares@yahoo.com.br

2 Universidade Federal do Rio Grande do Norte - UFRN. Professora do Departamento de Fundamentos e Políticas da Educação do Centro de Educação da Universidade Federal do Rio Grande do Norte. Email: gessicafabiely@hotmail.com

${ }^{3}$ Universidade Federal do Rio Grande do Norte - UFRN. Graduando do Curso de Ciências Biológicas da Universidade Federal do Rio Grande do Norte e Bolsista de Iniciação Científica. Orcid: http://orcid.org/0000-0002-8498-2501 Email: victorfaustino10@hotmail.com

${ }^{4}$ Universidade Federal do Rio Grande do Norte - UFRN. Graduando do Curso de Ciências Biológicas da Universidade Federal do Rio Grande do Norte. Orcid: http://orcid.org/0000-0001-9065-438X Email: samyrdbonifacio10@hotmail.com

${ }^{5}$ Universidade Federal do Rio Grande do Norte - UFRN. Graduando do Curso de Ciências Biológicas da Universidade Federal do Rio Grande do Norte. Orcid: http://orcid.org/0000-0002-2113-5188 Email: luizroberto1020@live.com 